Freud: a cien años de Tótem y tabú (1913-2013)

Néstor A. Braunstein, Betty B. Fuks, Carina Basualdo (Coord.)

México: Siglo XXI, 2013, 272 págs.

\title{
Freud: a cien años de Tótem y tabú
}

Adolfo Castañón

No es un libro accidental. Su cosecha e ingeniería se debe a una trinidad compuesta por Néstor Braunstein, Betty B. Fuks, Carina Basualdo, quienes convocaron a once autores de tres lenguas que se han reunido para marcar con sus contribuciones la vigencia polimorfa de la obra escrita por Sigmund Freud hace cien años, Tótem y tabú, donde psicología, etnología y antropología colindan. El libro se publica simultáneamente en tres lenguas: español, francés y portugués. El libro que presentamos es una obra, es decir, una construcción cuyos módulos comparten no sólo un lenguaje el del psicoanálisis - , un teclado de preocupaciones afines - las derivadas de la lectura de Jacques Lacan -, sino, más significativamente, los anima un entusiasmo crítico, una pasión por las ideas y las experiencias intelectuales que le imprimen a la obra un impulso propio y la hacen interesante para la filosofía, la antropología, la sociología, la teoría literaria y la historia - campos de interés de algunos de los autores aquí reunidos - y no sólo o no nada más, pero también desde luego, para la psicología y el psicoanálisis y sus respectivas historias. Interesante, desde luego, como ejercicio y prueba de oficio de escritura teórica. La construcción suscitada a seis manos desde el arco conceptual tensado por este libro practica 
una cartografía de la cultura y de la historia contemporáneas, a través de Sigmund Freud y del pensamiento desplegado en este libro por tantos motivos carismático y singular, titulado Tótem y tabú. Quizá no sería exagerado decir que los autores congregados en torno a esta mesa conmemorativa - Carina Basualdo, Néstor Braunstein, Octavio Chamizo, Anne Dufourmantelle, Betty Bernardo, Fuks Patricia Gherovici, Caterina Koltai, Daniel Koren, Paola Mieli, Jacques Nassif, Márcio Seligmann-Silva - están conscientes de que el libro comentado en cierto modo se contamina de la energía de la materia contenida en su título y que, cada uno a su manera, participa de ese ceremonial arcaico en torno a un libro que no sólo se titula Tótem y tabú, sino que en cierto modo lo es él mismo desde el momento mismo de su edición.

A un siglo de su publicación, el libro de Sigmund Freud se recuerda no sólo con las contribuciones mencionadas sino con un aparato propedéutico de relectura armado con cartas de Freud a Carl Gustav Jung, Sandro Ferenci, Ernest Jones, Wilhem Fliess, Oskar Pfister, Karl Abraham y un texto poco conocido de Thomas Mann. Estas palabras son muy significativas pues funcionan como el pasaporte que un gran escritor le extiende a otro, que un creador de mitos le hace llegar a otro. Ese aparato refuerza el efecto de los textos reunidos e insinúa al libro, en el horizonte del discurso, como un foco irradiador de fuerzas de atracción y rechazo conceptual y que sitúan al libro como un eje definidor de la discusión contemporánea. Otra forma de enunciar lo que aquí está en juego sería decir que tras la lectura de este libro inquietante y memorable por memorioso del pasado y del presente porvenir, se tiene, tenemos, tengo la sensación incómoda - el malestar — de encontrarme hablando no tanto o no sólo de un objeto de cultura, de un libro que se encuentra impreso y encuadernado fuera de mí - con su sugerente hélice multicolor de nombres — , sino de una obra suspendida en algún espacio del fuero interior. Otra manera de tratar de expresar esto sería decir que, a la hora de nacer este portavoz, en el año de 1952, Tótem y tabú tenía casi cuarenta años de publicado y que su materia misma se entrevera en las fibras mismas de nuestra identidad. Tótem y tabú ya estaba ahí antes de que todos los que estamos aquí naciéramos y forma parte de nuestra identidad cultural. Por eso el libro no versa sobre del pasado remoto, no es ni con mucho un ejercicio de arqueología, ni mucho menos, se presenta más bien como una invitación ferozmente contemporánea a abrir y tratar de comprender las entrañas del presente para intentar leer en ellas, como los oficiantes antiguos, ya no sólo el pasado inmediato y su atroz memoria (por ejemplo, la del Holocausto, que cambió la vida de Freud, de la cultura europea y de la lectura misma del texto comentado), sino del ominoso, acechante presente en que ese pasado inmediato se prolonga y donde, por poner un ejemplo, la figura del padre ya no sólo ha sido sometida a una obliteración y supresión, incluso en el avatar del Hermano Mayor (Big Brother), sino que se encuentra diluido en la puntuación misma de la ultimada 


\section{RESENHA DE LIVROS}

modernidad, en ese signo totémico intocable que es la @ como muestra o vuelve a mostrar Néstor A. Braunstein. El texto del autor de Traducir el psicoanálisis es uno de los discursos centrales del libro. No cabe glosarlo aquí, pero sí me gustaría destacar algunas fortalezas de su exposición: el tema muy visible del Big Brother de George Orwell, y otro, menos visible, el de la utopía aséptica de John Rawls al postular los principios de una justicia social en el mundo moderno. Otra fortaleza del ensayo de Braunstein es el rescate o relectura del Antiedipo de Gilles Deleuze.

A cien años de Tótem y tabú (1913-2013) se abre al sesgo como un juego de constancias del siglo y de miradas que van anotando al margen como apostillas, escolios o lecturas tangenciales (así se subtitula de hecho la contribución de Oscar Chamizo, director de la colección donde el libro aparece "Lectura tangencial de Tótem y tabú", "En el principio era el acto"), sobre o hacia la historia y la historia de las ideas contemporáneas como en el ensayo "Entre Freud y Lacan hay Bataille") donde Jacques Nazzif reconoce un triple tándem en que se relevan y triangulan Freud, Bataille y Lacan, el arreglo de estas miradas tiene en filigrana algo de teatral o, mejor todavía, de acción colectiva. No se toca gratuitamente el asunto ignominioso de Auschwitz y su mañana en el escrito a cuatro manos, o faena al alimón para emplear una voz taurina, realizada admirablemente por Betty B. Fuks y Catherine Kottai, ni se cala en la escatología y el pensamiento freudiano en un escrito olvidado sin la conciencia de que se está de algún modo actuando. El repaso de la cultura contemporánea a través de Tótem y tabú prosigue en el contraste de las mitografías de Una nueva versión del mito de la horda parricida: las estructurales elementales del parentesco de Claude Levi-Strauss, de Carina Basualdo y se afina en las dos contribuciones finales "El mito científico de la era de las catástrofes" y Marcio Seligman Silva y ese brillante ejercicio de teoría política que lleva por título "La resurgencia del tirano como inscripción denegada de la constitución de la fratría" de Paulo Endo. Esas ideas políticas esbozan el planteamiento no sólo de un derecho posible posterior al Holocausto que quebrantó la posibilidad misma de todo derecho, sino que propone una ética de la cultura y del pensamiento que quizá resume en su último párrafo el espíritu con que está concebida esta máquina de pensar que es también una máquina de resistencia intelectual, una escala de lápidas soberbias que tienen como destino al lector.

La muerte figura, por lo tanto, como consecuencia de la exigencia radical de propiedad; el mayor y más convincente acto de testimonio se daría en virtud de la muerte y de la verdad que esa expone. Aquellos que han sido asesinados, exterminados serían, de ese modo, los únicos que podrían afirmar una única y definitiva vez la verdad radical; esa, bajo la que todos aquellos que hablen luego, los sobrevivientes, deben guardar secreto (o ignorancia) en tanto que hablan, y aún así seguir dejando sus grafismos en las ruinas — piedras soberbias sin destino - esas 
inscripciones que, una vez encontradas en la superficie ruda y rocosa, jamás podrán levantarse. (p. 265)

Un libro tan bien ensamblado como éste parece como una de esas construcciones barrocas donde cada estancia, cada escalera, cada capítulo se buscan en su revés y la memoria cobra cuerpo en una tonificante visión estereoscópica que seguramente no hubiese disgustado al hijo de aquel humilde comerciante en artículos de lana - Sigmund Freud - que a los 55 años de edad escribió un texto inagotable, una obra, como dice Anne Dufourmantelle, que puede ser tocada, interpretada una y otra vez. Gracias a Néstor, Betty y Carina.

Quizá, para tratar de plantar un par de banderillas críticas a este minotauro antológico, cabría sugerir que para una próxima edición alguien más que este lector pudiese plantear una reflexión sobre lo que significó en continuidad y en ruptura y en el seno del desarrollo del pensamiento de Sigmund Freud la escritura y la publicación de esta obra tan singular que lo situaba en las fronteras mismas de la disciplina a la que había avistado y dado cuerpo y realidad discursiva... Más allá de Frazer, más acá de Wittgenstein Tótem y tabú, en efecto, cabría ser leído bajo esta luz como un acto de incomparable audacia intelectual y de arrojo crítico que pondría al discurso psicoanalítico en el eje de una indagación filosófica más amplia y ambiciosa en el horizonte de la cual se inscribiría desde luego y en primer lugar el pensamiento de Jacques Lacan.

La otra observación es de muy otra índole: para un lector mexicano, la fecha de 1913 es sinónimo de la Decena Trágica en que perdieron la vida Francisco I. Madero y José María Pino Suárez para ceder el lugar a Victoriano Huerta, cuya caída a su vez inauguraría la historia moderna de México y sus instituciones. Uno de los protagonistas en esos tristes episodios fue el general Bernardo Reyes - figura totémica de la historia mexicana - quien sucumbió la madrugada del segundo domingo de febrero de 1913, dando lugar a que su hijo Alfonso Reyes escribiera la catártica Oración del 9 de febrero, pieza clave de las letras mexicanas modernas. Una atrevida aproximación al libro Tótem y tabú realizada desde México a cien años de su publicación quizá sabría desarmar aquél rompecabezas, no hay en verdad otra palabra, de nuestra historia con el instrumental que proporciona Freud, con su escritura y pensamiento. De ese ejercicio saldría una estremecedora y quizá escandalosa versión de la intrahistoria palpitante en México y tal vez hilo conductor para salir o para adentrarse más en el laberinto.

\section{Adolfo Castanón}

Poeta, ensaísta, editor e crítico literário mexicano. 